A new year is upon us in a new democratic society with exciting changes also envisaged for the SASP. The restructuring process has been a long and arduous one and all credit must go to the small group of people who have spent so much of their time and energies on this project. Most members of the SASP have had the opportunity to hear about the proposed changes and will be asked to vote for restructuring at the next Council meeting. The aim of restructuring is to allow members to become more intimately involved in the running of the Society. Of course the plan is not foolproof, but does deserve to be tried out and will surely be refined over the years to come.

\section{READERS' NEEDS}

What is it that members want from the SA Journal of Physiotherapy? In a survey undertaken by the Publications Division, it was found that physiotherapists were satisfied with both publications of the SASP. In the small sample interviewed, practitioners felt that they would also like more case studies and short reports of a less scientific nature. These will always be published, when available, together with research driven studies and review articles.

But where are these research articles to come from? We have a very small group of post-graduate students from which to draw and many articles of a reasonable standard are received from authors outside the profession. They do meet the criteria of professionalism but often are of little or no relevance to our readers.

Do we publish these articles of little relevance in order to maintain "stand- ards" or do we aim to cater for all our members who may not be so efficient or skilled in interpreting research articles? In an ideal world, the Editorial Board would have a bank of well written research articles from which to choose. Although many articles are rejected, we often have to use articles which may not be described as research but which may be of interest to practitioners.

All these ponderings have come about through a letter written to the Editor which is published, in part, in this edition of the Journal. Although as Editor, I would like to see the Journal meeting "International Standards", I do wonder if this is the main aim of our publication whose mission is to communicate and to educate in order to share knowledge and experiences. What do our readers think and what path should we be following?

\section{CONTENTS}

This edition of the Journal was to have been devoted to neurology, but only one article was received in time for publication. L Hale et al describe the study that they undertook to establish what the optimal time of applying passive muscle stretch would be in order to reduce spasticity in the quadriceps muscles of patients following cerebral lesions.

Three reports and/or case studies are presented by members of the Orthopaedic Manipulative Therapists Group which should be of interest to those dealing with rotator cuff problems, cauda equina syndromes and cervical disorders.

The Editorial Board is most grateful for the time and patience of our referees and a list is published of those practitioners and referees who have assisted in reviewing articles during the past year. Theirs is an onerous task as not only do they check the content and style but also make suggestions for improvement of the articles.

Once again an appeal is made to our readers to submit articles to our Journal, whether they be based on scientific research or on carefully controlled and documented case studies. The May 1995 edition will be devoted to various aspects of paediatrics and articles must reach the editor before the end of February. The Journal in August will hopefully comprise articles relating to community and education issues while November will again be devoted to Exercise and Sport. All articles must be submitted at least three months in advance, but a longer period is desirable to allow for corrections to be made if necessary.

The Editorial Board will also be grateful for suggestions on how we may improve the Journal and do let us know if you are satisfied with the publication and whether it is meeting your needs.

\section{ARTICLE REFEREES}

Referees who have assisted in reviewing articles for publication in the Journal over the past year.

- Mrs Jenny Mitchell

- Miss Sheena Irwin-Carruthers

- Mrs Sielie Eales

- Professor Geoff Rogers

- Mrs Carol Cunningham

- Miss Mariette Uys

- Miss Jenny Hendry

- Mrs Jo-Anne Sklaar

The Editorial Board is most grateful for their assistance in this time consuming task. 